\title{
Long-term prevention of diabetic nephropathy: an audit
}

\author{
K. J. Schjoedt • H. P. Hansen • L. Tarnow • P. Rossing • \\ H.-H. Parving
}

Received: 2 October 2007 / Accepted: 12 February 2008/Published online: 3 April 2008

(C) Springer-Verlag 2008

\begin{abstract}
Aims/hypothesis In type 1 diabetic patients with microalbuminuria not receiving antihypertensive treatment, an increase in urinary AER (UAER) of 6-14\%/year and a risk of developing diabetic nephropathy (DN) of 3-30\%/year have been reported. We audited the long-term effect of blocking the renin-angiotensin-aldosterone system (RAAS) with an ACE inhibitor (ACEI) or angiotensin II receptor blocker (ARB) in microalbuminuric type 1 diabetic patients on progression of microalbuminuria and development of DN. Methods All patients with type 1 diabetes and persistent microalbuminuria $(30-300 \mathrm{mg} / 24 \mathrm{~h})$ were identified $(n=227)$ in 1995 at Steno Diabetes Center and followed for 11 years. Development of DN was defined as a UAER of $>300 \mathrm{mg} / 24 \mathrm{~h}$ in two of three consecutive urine samples. Results Age and duration of diabetes at baseline (mean $\pm \mathrm{SD}$ ) were $46 \pm 15$ and $28 \pm 13$ years, respectively. During followup 14 patients emigrated and $58(26 \%)$ died. Over the same
\end{abstract}

Electronic supplementary material The online version of this article (doi:10.1007/s00125-008-0990-3) contains supplementary material, which is available to authorised users.

K. J. Schjoedt $(\bowtie) \cdot$ H. P. Hansen $\cdot$ L. Tarnow $\cdot$ P. Rossing

Steno Diabetes Center,

Niels Steensens Vej 1,

2820 Gentofte, Denmark

e-mail: kjos@steno.dk

H.-H. Parving

Department of Medical Endocrinology, Rigshospitalet,

University Hospital of Copenhagen,

Copenhagen, Denmark

H.-H. Parving

Faculty of Health Science, University of Aarhus,

Aarhus, Denmark period $79 \%$ were treated with an ACEI or ARB. There was a mean decline in UAER of 4\%/year. Sixty-five patients (29\%) progressed to overt DN, corresponding to 3.1\%/year. However, 29 of them regressed to normo- or microalbuminuria on intensified antihypertensive treatment. Glycaemic control and blood pressure remained nearly unchanged.

Conclusions/interpretation In our outpatient clinic, the implementation of RAAS-blocking treatment in type 1 diabetic patients with microalbuminuria successfully reduced longterm progression to overt $\mathrm{DN}$ to a rate similar to those previously reported in randomised, double-blind intervention trials of shorter duration using RAAS blockade.

Keywords ACE inhibitors - Angiotensin II receptor blockers · Audit - Diabetic nephropathy · Microalbuminuria . Prevention - RAAS blockade $\cdot$ Renin-angiotensinaldosterone system $\cdot$ Renoprotection $\cdot$ Type 1 diabetes

$\begin{array}{ll}\text { Abbreviations } \\ \text { ACEI } & \text { ACE inhibitor } \\ \text { ARB } & \text { angiotensin II receptor blocker } \\ \text { DN } & \text { diabetic nephropathy } \\ \text { eGFR } & \text { estimated GFR } \\ \text { ESRD } & \text { end-stage renal disease } \\ \text { RAAS } & \text { renin-angiotensin-aldosterone system } \\ \text { SDC } & \text { Steno Diabetes Center } \\ \text { UAER } & \text { urinary AER }\end{array}$

\section{Introduction}

Diabetic nephropathy develops in approximately $30 \%$ of diabetic patients and is the most common cause of endstage renal disease (ESRD) in the western world. Micro- 
albuminuria has previously been demonstrated to precede and predict the development of diabetic nephropathy in type 1 diabetic patients. In type 1 diabetic patients with microalbuminuria not receiving antihypertensive treatment, an increase in urinary AER (UAER) of 6-14\%/year and a risk of developing diabetic nephropathy (DN) of 3-30\%/year have previously been reported [1-10]. Several clinical trials of short or medium duration have shown a beneficial effect of blocking the renin-angiotensin-aldosterone system (RAAS) with an ACE inhibitor (ACEI) on progression of albuminuria, the development of diabetic nephropathy and the decline in kidney function [6, 7, 9-15]. Angiotensin II receptor blockers (ARBs) have been shown to have a similar effect in type 2 diabetic patients with microalbuminuria [16]. In 1995, a consensus report on the detection, prevention and treatment of diabetic nephropathy with special reference to microalbuminuria recommended treatment with ACEIs and improved glycaemic control $\left(\mathrm{HbA}_{1 \mathrm{c}}\right.$ below 7.5-8.0\%) [17]. A slightly modified version of these guidelines was implemented in our outpatient clinic at Steno Diabetes Center (SDC) in 1995.

The renoprotective effect of long-term RAAS blockade in microalbuminuric type 1 diabetic patients in a clinical setting has not been evaluated previously. The aim of our 11 year observational follow-up study was to audit how successful we had been in implementing the new treatment and to audit the effect of RAAS-blocking treatment in microalbuminuric type 1 diabetic patients on the progression of microalbuminuria and development of DN in the clinical setting of our outpatient clinic at SDC.

\section{Methods}

Patients and data acquisition From our patient register at SDC, all type 1 diabetic patients with persistent microalbuminuria (UAER $>30$ and $<300 \mathrm{mg} / 24 \mathrm{~h}$ in two of three consecutive urine samples) were identified in the first week of January 1995, as described previously [18]. A total of 227 type 1 diabetic patients with persistent microalbuminuria were included for follow-up.

At baseline, patients were divided according to the level and/or rate of progression of UAER during the 2 years prior to 1 January 1995 into a group at high risk (UAER $\geq 100 \mathrm{mg} / 24 \mathrm{~h}$ and/or $\triangle$ UAER $>6 \% /$ year) and a group at low risk (UAER $<100 \mathrm{mg} / 24 \mathrm{~h}$ and $\triangle \mathrm{UAER} \leq 6 \% /$ year) of developing DN. In accordance with international guidelines [17], patients at high risk of developing $\mathrm{DN}$ were recommended treatment with an ACEI, and if $\mathrm{HbA}_{1 \mathrm{c}}$ was $>8 \%$ these patients were also offered intensive nurse guidance in order to improve glycaemic control. Patients in the low-risk group were prescribed an ACEI only if this was considered appropriate by the individual's physician (until 2002).
In 2002 the recommendations at SDC were extended to include ACEI treatment in all patients with microalbuminuria (independent of high- and low-risk status); furthermore, statins and low-dose aspirin ( $75 \mathrm{mg}$ daily) were recommended for all these patients. Patients who did not tolerate ACEIs were prescribed ARBs. Additional antihypertensive treatment was prescribed as considered appropriate by the individual physician if blood pressure exceeded $140 / 90 \mathrm{mmHg}$, in order to reach a target blood pressure of $130 / 85 \mathrm{mmHg}$.

During follow-up, patients were seen three or four times a year for routine visits in our outpatient clinic at SDC. At each visit, blood pressure, blood glucose, $\mathrm{HbA}_{1 \mathrm{c}}$ and UAER were measured. Patients were followed until 31 December 2005 or until death or emigration.

Progression to overt diabetic nephropathy was defined as albuminuria $\geq 300 \mathrm{mg} / 24 \mathrm{~h}$ in two of three consecutive urine samples. Regression to normo- or microalbuminuria from overt diabetic nephropathy was defined as UAER within the normoalbuminuric (UAER $<30 \mathrm{mg} / 24 \mathrm{~h}$ ) or microalbuminuric (UAER $\geq 30 \mathrm{mg} / 24 \mathrm{~h}$ and $<300 \mathrm{mg} / 24 \mathrm{~h}$ ) range in at least the last three consecutive urine samples.

Patients were followed with yearly measurements of serum creatinine using the same method (Cobas Mira Plus; Roche Diagnostics, Mannheim, Germany) until the end of 2003 and GFR was estimated (using the modification of diet in renal disease [MDRD] equation) [19]. The decline in estimated GFR was calculated from 1995 to 2003 in patients with at least three measurements and $\geq 3$ years of follow-up $(n=169)$. In 2004 a new method for measuring creatinine, which did not allow direct comparison with previous measurements, was introduced at SDC.

The data used were from our patients' case records, clinical data from other clinics (for emigrated patients) and death certificates. The vital status of all patients was evaluated in the National Death Certificate Registry at 31 December 2005. Treatment and renal status are given as last known values (all patients, $n=227$ ), which was the basis for calculating follow-up times.

A 4 year follow-up of the present cohort was published in 2001 [18]. The study was performed according to the principles of the Declaration of Helsinki and approved by the Danish Data Protection Agency and by the Institutional Review Board at Steno Diabetes Center.

Statistics Normally distributed variables are expressed as means \pm SD (baseline) and means \pm SE (follow-up). Values for UAER were logarithmically transformed owing to their skewed distribution and are given as geometric mean $(95 \%$ CI). All measurements were made regularly during followup and each data variable was averaged for each year. Furthermore, systolic and diastolic blood pressures and $\mathrm{HbA}_{1 \mathrm{c}}$, measured during 1996-2005, were averaged (follow-up) and compared with values from 1995 (baseline). Linear regres- 
sion analysis was used to determine the rate of progression in UAER (slope) during the study period (1995-2005) using all available measurements of UAER. The paired samples $t$ test was used to compare continuous variables (baseline vs follow-up). Comparisons between groups were performed with the $\chi^{2}$ test. Linear regression analysis was used to analyse for correlations between the relative change in albuminuria and baseline variables, and between changes in UAER and changes in arterial blood pressure and $\mathrm{HbA}_{1 \mathrm{c}}$. Cumulative incidence curves (based on survival analysis) for time to progression to DN, persistent macroalbuminuria and regression to normoalbuminuria are shown in the Electronic supplementary material (ESM). Significance was indicated by $p$ values $<0.05$ (two-sided). Data were evaluated using SPSS version 14.0 (SPSS, Chicago, IL, USA).

\section{Results}

A total of 227 type 1 diabetic patients with microalbuminuria were identified at SDC in January 1995. Fifty-eight patients died during follow-up; death certificates were available for all of these patients. Twenty-nine patients moved to other clinics, and data on current treatment and renal status were obtained in 15 of these patients; the remaining 14 patients were lost to follow-up after a median period of 3.5 years (range 0.5-9.5). Last data from SDC were used for these patients, who were not attending any nephrology or cardiology clinic at the end of follow-up according to the National Health Registry. Overall, patients were followed up for a median (range) time of 11.0 (0.511.0) years. The mean follow-up time, 9.3 (SD 3.0) years, was used to calculate annual progression rates from microto macroalbuminuria. Baseline characteristics and follow-up data are given in Table 1.

Treatment Throughout the study, $79 \%$ of the patients were treated with an RAAS-blocking agent (ACEI 64\%, ARB $15 \%)$. For patients who were attending SDC at the end of follow-up the percentage was 85\% (ACEI 64\%; ARB 21\%). Patients who received ARBs did not differ from ACEItreated patients regarding sex, age, progression of albuminuria or development of DN. The median (range) number of antihypertensive drugs used in order to obtain the target blood pressure of 130/85 was 2 (0-5). Diuretics and calcium channel blockers were the most commonly used additional antihypertensive drugs, but also prescribed were beta-blockers, alpha-blockers, aldosterone antagonists, centrally acting antihypertensive drugs, and drugs for dual blockade of the RAAS (ACEI plus ARB). Statins and low-dose aspirin were prescribed in 61 and 57\% of the patients at SDC in 2005 (27 and $20 \%$, respectively, in patients attending other clinics).
Table 1 Clinical and laboratory characteristics of 227 type 1 diabetic patients with persistent microalbuminuria in 1995 (baseline) and during follow-up

\begin{tabular}{|c|c|c|}
\hline & Baseline & Follow-up \\
\hline Age (years) & $46 \pm 15$ & - \\
\hline Diabetes duration (years) & $28 \pm 13$ & - \\
\hline $\mathrm{HbA}_{1 \mathrm{c}}(\%)$ & $8.8 \pm 1.0$ & $8.7 \pm 1.0^{\mathrm{a}}$ \\
\hline $\begin{array}{l}\text { Urinary albumin excretion } \\
(\mathrm{mg} / 24 \mathrm{~h})\end{array}$ & $65(58-74)$ & $52(44-61)^{\mathrm{a}}$ \\
\hline $\begin{array}{l}\text { Systolic blood pressure } \\
(\mathrm{mmHg})\end{array}$ & $142 \pm 20$ & $141 \pm 17$ \\
\hline $\begin{array}{l}\text { Diastolic blood pressure } \\
(\mathrm{mmHg})\end{array}$ & $80 \pm 9$ & $77 \pm 7^{\mathrm{a}}$ \\
\hline eGFR $\left(\mathrm{ml} \mathrm{min} \min ^{-1} 1.73 \mathrm{~m}^{-2}\right)$ & $81 \pm 18$ & - \\
\hline \multicolumn{3}{|l|}{ 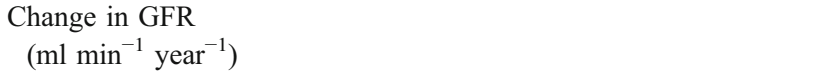 } \\
\hline Overall & - & $-2.1(-2.5$ to -1.7$)$ \\
\hline Patients not developing DN & - & $-2.0(-2.4 \text { to }-1.6)^{\mathrm{b}}$ \\
\hline Patients developing DN & - & $-2.5(-3.4$ to -1.6$)$ \\
\hline
\end{tabular}

Data are means $\pm \mathrm{SD}$ except for urinary albumin excretion, which is given as geometric mean $(95 \% \mathrm{CI})$

${ }^{\mathrm{a}} p<0.01$ vs baseline

${ }^{\mathrm{b}}$ Not significant vs patients developing DN $(p=0.21)$

Progression of UAER Overall, there was a mean \pm SE decline in UAER of $4.0 \pm 2.1 \% /$ year during follow-up. During the 11 years of follow-up, 65 patients (29\%) progressed to overt $\mathrm{DN}$, corresponding to $3.1 \%$ year. However, 23 of these patients regressed to microalbuminuria and six to normoalbuminuria as a result of increased doses of RAAS-blocking treatment $(n=22)$ or the addition of other antihypertensive drugs $(n=7)$, i.e. only $1.7 \%$ year of 227 microalbuminuric patients had progressed to persistent macroalbuminuria at the end of follow-up. In 2005, 32\% of the 140 patients still attending SDC were normoalbuminuric, $55 \%$ were microalbuminuric and $13 \%$ were macroalbuminuric. Cumulative incidence curves for progression to DN, persistent macroalbuminuria and regression to normoalbuminuria are given in ESM Figs 1, 2 and 3, respectively.

There was no association between changes in UAER and the baseline variables of UAER $(r=0.09, p=0.2)$, age, diabetes duration, blood pressure, $\mathrm{HbA}_{1 \mathrm{c}}$ and high- vs lowrisk status ( $p \geq 0.1$ for all comparisons). Furthermore, there was no correlation between changes in UAER and blood pressure during follow-up. However, there was a weak but statistically significant correlation between changes in UAER and $\mathrm{HbA}_{1 \mathrm{c}}$ during follow-up $(r=0.15, p<0.05)$. Patients who were in the high-risk group at baseline had a threefold higher risk of progressing to overt DN compared with the low-risk group (34 vs $10 \%, p=0.001$ ).

Estimated GFR Baseline estimated GFR (eGFR) and changes in eGFR are shown in Table 1. There was no statistically significant difference in annual change in eGFR between 
patients who did or did not progress to DN. At the end of follow-up eGFR was, however, significantly lower in the $\mathrm{DN}$ group (mean $\pm \mathrm{SE}, 64 \pm 3 \mathrm{ml} \mathrm{m^{-1 }} 1.73 \mathrm{~m}^{-2}$ ) than in patients who did not develop DN $\left(71 \pm 2 \mathrm{ml} \mathrm{min}^{-1} 1.73 \mathrm{~m}^{-2}\right.$; $p<0.05)$.

Two patients had a doubling of serum creatinine but the eGFR at the end of follow-up was 37 and $41 \mathrm{ml} \mathrm{min}^{-1}$ $1.73 \mathrm{~m}^{-2}$, respectively. Three patients developed ESRD according to their death certificates (see "Cardiovascular events and mortality", below), but they all moved to other clinics before developing ESRD and therefore do not appear among the patients with doubling of serum creatinine.

Glycaemic control and blood pressure Baseline and followup data are given in Table 1. After 11 years of follow-up there was an overall decrease in $\mathrm{HbA}_{1 \mathrm{c}}$ of $0.2(0.1-0.3)$ from a mean $\pm \mathrm{SE} \mathrm{HbA}_{1 \mathrm{c}}$ of $8.8 \pm 0.1 \%, p<0.01$. Systolic blood pressure remained unchanged during follow-up $(p=0.5)$, whereas a decrease in diastolic blood pressure of $2.4 \mathrm{mmHg}$ (95\% CI 1.4-3.3) was obtained $(p<0.001)$.

Cardiovascular events and mortality Table 2 shows fatal and non-fatal cardiovascular events with patients grouped according to DN status. There were no significant differences between patients who had developed DN and those who had not in the incidence of cardiovascular events or mortality.

During follow-up, 58 patients died. The cause of death was cardiovascular disease in $24(41 \%)$ patients, ESRD in 3 (5\%) patients, 'other diseases' (i.e. cancer, acute diabetic complications, infections) in $19(33 \%)$ patients and unknown causes in $12(21 \%)$ patients. The mean $\pm \mathrm{SE}$ age at the time of death was $67 \pm 1$ years and the mean duration of diabetes was $44 \pm 2$ years.

\section{Discussion}

In our 11 year observational follow-up study evaluating the renoprotective effect of implementing RAAS-blocking treat- ment in type 1 diabetic patients with microalbuminuria, we found an overall decrease in UAER during follow-up and a reduction in progression to overt DN similar to values found in previous randomised, double-blind RAAS-blockade intervention trials of shorter duration [11-15]. In the present study, long-term RAAS-blocking treatment was prescribed in $85 \%$ of type 1 diabetic patients with microalbuminuria and low-dose aspirin and statins in approximately 60\% (at the end of follow-up). Only ten of 227 patients did not comply with therapy because of adverse effects.

In previous studies not using RAAS-blocking treatment, an annual increase in UAER of $5-70 \%$ in type 1 diabetic patients with microalbuminuria has been reported $[4,5,7-$ 10]. In contrast, we found an overall decrease in UAER after the introduction of RAAS-blocking treatment.

Furthermore, a progression rate from micro- to macroalbuminuria of roughly $80 \%$ was originally reported during an observation period of 10-14 years in type 1 diabetic patients not receiving RAAS-blocking treatment [1-3]. Subsequently, multiple trials have looked at progression rates from micro- to macroalbuminuria and reported progression rates ranging from 5.6 to $30 \% /$ year [5-10]. Intervention trials have demonstrated that ACEIs reduce the progression from micro- to macroalbuminuria and preserve GFR in type 1 diabetic patients [11-15]. Chaturvedi and colleagues conducted a large scale meta-analysis of studies comparing intervention groups (treated with ACEIs) with placebo groups [15]. The progression rate from microto macroalbuminuria in the placebo arm was $15.6 \%$ /year (N. Chaturvedi, National Heart and Lung Institute, Imperial College at St Mary's, London, UK, personal communication), whereas progression to macroalbuminuria was reduced in patients receiving ACEI (OR 0.38, 95\% CI 0.25 0.57) [15]. Similar results with ARBs have been reported in type 2 diabetic patients [16].

In our observational follow-up study, implementation of RAAS blockade in type 1 diabetic patients reduced the progression to overt diabetic nephropathy to $3.4 \%$ /year. It should be noted that $45 \%$ of patients progressing to DN subsequently regressed to micro- or normoalbuminuria on

Table 2 Cardiovascular events and mortality in 227 microalbuminuric patients according to development of diabetic nephropathy during 11 years of follow-up

\begin{tabular}{|c|c|c|c|}
\hline & Patients without DN $(n=162)$ & Patients with DN $(n=65)$ & $p$ value \\
\hline Fatal or non-fatal AMI or CABG or CHF & $17 \%$ & $15 \%$ & 0.84 \\
\hline Fatal or non-fatal stroke or TCI & $12 \%$ & $19 \%$ & 0.26 \\
\hline PAS or amputation & $10 \%$ & $10 \%$ & 1.00 \\
\hline Total number of patients with fatal or non-fatal cardiovascular events ${ }^{\mathrm{a}}$ & $32 \%$ & $38 \%$ & 0.52 \\
\hline Total mortality & $27 \%$ & $22 \%$ & 0.41 \\
\hline
\end{tabular}

AMI, acute myocardial infarction; CABG, coronary arterial bypass grafting; CHF, chronic heart failure; TCI, transitory cerebral ischaemia; PAS, peripheral arterial surgery

${ }^{\text {a }}$ Patients with one or more fatal or non-fatal events 
intensified antihypertensive treatment; i.e. only $1.7 \% /$ year progressed to persistent macroalbuminuria after 11 years of follow-up.

At the end of follow-up the cumulative incidence of developing DN in our study was $29 \%$, which is similar to (although somewhat lower than) the incidence in a previous study [20]; this suggests that RAAS blockade may not prevent but rather delay the progression to DN. The benefit of a delay in progression to DN is obvious since kidney function has been shown to be preserved until progression to DN [11]. Furthermore, aggressive antihypertensive treatment in type 1 diabetic patients with DN has improved the prognosis of diabetic nephropathy in type 1 diabetes [21].

Progression from microalbuminuria to $\mathrm{DN}$ was associated with $\mathrm{HbA}_{1 \mathrm{c}}$ levels during follow-up in our study. This is in accordance with previous observational studies finding the same association between poor glycaemic control and progression in albuminuria and the rate of progression to $\mathrm{DN}$ [20, 22-25]. In our study, an effort was made to obtain improved glycaemic control by intensive nurse guidance. The results, however, were disappointing, with only a small decrease in $\mathrm{HbA}_{1 \mathrm{c}}$. There was no association between changes in UAER and blood pressure, in agreement with previous findings in normotensive type 1 diabetic patients with microalbuminuria [26].

During follow-up, $26 \%$ of the patients died. This must be regarded as an improvement in survival; i.e. our group previously reported a similar mortality in a 10 year observational follow-up study [27] in 181 type 1 diabetic patients with microalbuminuria followed from 1984, i.e. before the introduction of routine RAAS-blocking treatment in patients with microalbuminuria. The patients in the present study were, however, 8 years older and had a diabetes duration that was 7 years longer at baseline compared with the patients in the previous study [27]. In the present study, only three patients died from ESRD whereas 24 died of known cardiovascular disease. There was no difference in the incidence of cardiovascular events and mortality when patients progressing to overt DN were compared with patients who did not develop DN. Overall mortality was reduced to a similar level in the two groups. The lack of difference between DN and non-DN patients is unclear but may have been due partly to the short duration of DN (median follow-up with DN 6.5 years, range 0.5-10.5) and consequently well-preserved kidney function. Furthermore, it should be noted that approximately half of the patients regressed to micro- or normoalbuminuria, thereby reducing markedly their risk of cardiovascular events and ESRD [28, 29]. Moreover, microalbuminuria per se is a well-established risk factor for cardiovascular disease [30], which may further diminish the difference in prognosis regarding cardiovascular disease and mortality between patients with persistent microalbuminuria and patients with DN. The introduction of routine use of low-dose aspirin and statins in patients with microalbuminuria and DN in 2002 in our study is expected to have contributed to the reductions in mortality and cardiovascular events that we observed. However, the guidelines are the same in microalbuminuric patients and patients with DN, and therefore do not explain the lack of difference between these groups.

Our encouraging results must be regarded as conservative since drug compliance in the treatment of chronic asymptomatic disease has been reported to be as low as $40-80 \%$ [31]. There are also limitations to an audit like this. First, we do not have complete follow-up data on all included patients; 14 patients were lost to follow-up in relation to the development of diabetic nephropathy after a median of 3.5 years. However, these patients were alive at the end of follow-up and we were able to rule out the possibility that these patients had been hospitalised in a nephrology or cardiology ward from the National Health Registry. Second, we may have underrated the number of non-fatal cardiovascular events because this information came from our patients' case records, which may be incomplete.

In conclusion, we found that it was feasible to implement RAAS-blocking treatment as standard therapy in type 1 diabetic patients with microalbuminuria in a clinical setting. This reduced the long-term rate of progression to overt DN to a rate similar to those observed in randomised, doubleblind RAAS-blockade intervention trials of shorter duration.

Acknowledgements We acknowledge the assistance of B. V. Hansen and B. R. L. Molsing in extracting data from our database.

Duality of interest The authors declare that there is no duality of interest associated with this manuscript.

\section{References}

1. Parving H-H, Oxenbøll B, Svendsen PA, Christiansen JS, Andersen AR (1982) Early detection of patients at risk of developing diabetic nephropathy. Acta Endocrinol 100:550-555

2. Viberti GC, Hill RD, Jarrett RJ, Argyropoulos A, Mahmud U, Keen H (1982) Microalbuminuria as a predictor of clinical nephropathy in insulin-dependent diabetes mellitus. Lancet i:1430-1432

3. Mogensen CE, Christensen CK (1984) Predicting diabetic nephropathy in insulin-dependent patients. N Engl J Med 311:89-93

4. Mathiesen ER, Oxenbøll B, Johansen K, Svendsen PA, Deckert T (1984) Incipient nephropathy in type 1 (insulin-dependent) diabetes. Diabetologia 26:406-410

5. Feldt-Rasmussen B, Mathiesen ER, Deckert T (1986) Effect of two years of strict metabolic control on progression of incipient nephropathy in insulin-dependent diabetes. Lancet ii:1300-1304

6. Marre M, Chatellier G, Leblanc H, Guyenne T-T, Ménard J, Passa P (1988) Prevention of diabetic nephropathy with enalapril in normotensive diabetics with microalbuminuria. BMJ 297:1092-1095

7. Mathiesen ER, Hommel E, Giese J, Parving H-H (1991) Efficacy of captopril in postponing nephropathy in normotensive diabetic patients with microalbuminuria. BMJ 303:81-87 
8. Bangstad H-J, Østerby R, Dahl-Jørgensen K, Berg K, Hartmann A, Hanssen KF (1994) Improvement of blood glucose control in IDDM patients retards the progression of morphological changes in early diabetic nephropathy. Diabetologia 37:483-490

9. The Microalbuminuria Captopril Study Group (1996) Captopril reduces the risk of nephropathy in IDDM patients with microalbuminuria. Diabetologia 39:587-593

10. Crepaldi G, Carta Q, Deferrari G et al (1998) Effects of lisinopril and nifedipine on the progression of overt albuminuria in IDDM patients with incipient nephropathy and normal blood pressure. Diabetes Care 21:104-110

11. Mathiesen ER, Hommel E, Hansen HP, Smidt UM, Parving H-H (1999) Randomised controlled trial of long term efficacy of captopril on preservation of kidney function in normotensive patients with insulin dependent diabetes and microalbuminuria. BMJ 319:24-25

12. Viberti GC, Mogensen CE, Groop L, Pauls JF, the European Microalbuminuria Captopril Study Group (1994) Effect of captopril on progression to clinical proteinuria in patients with insulin-dependent diabetes mellitus and microalbuminuria. JAMA 271:275-279

13. Laffel LMB, McGill JB, Gans JD (1995) The beneficial effect of angiotensin-converting enzyme inhibition with captopril on diabetic nephropathy in normotensive IDDM patients with microalbuminuria. Am J Med 99:497-504

14. The Euclid Study Group (1997) Randomised placebo-controlled trial of lisinopril in normotensive patients with insulin-dependent diabetes and normoalbuminuria or microalbuminuria. Lancet 349: $1787-1792$

15. The ACE Inhibitors in Diabetic Nephropathy Trialist Group (2001) Should all type 1 diabetic microalbuminuric patients receive ACE inhibitors? A meta-regression analysis. Ann Intern Med 134:370-379

16. Parving H-H, Lehnert H, Bröchner-Mortensen J, Gomis R, Andersen S, Arner P (2001) The effect of irbesartan on the development of diabetic nephropathy in patients with type 2 diabetes. $\mathrm{N}$ Engl $\mathrm{J}$ Med 345:870-878

17. Mogensen CE, Keane WF, Bennett PH et al (1995) Prevention of diabetic renal disease with special reference to microalbuminuria. Lancet 346:1080-1084

18. Hansen HP, Lund SS, Rossing P et al (2001) Preventing diabetic nephropathy: an audit. Scand J Clin Lab Invest 61:471-477
19. Levey AS, Bosch JP, Lewis JB, Greene T, Rogers N, Roth D (1999) A more accurate method to estimate glomerular filtration rate from serum creatinine: a new prediction equation. Modification of Diet in Renal Disease Study Group. Ann Intern Med 130:461-470

20. Rossing P, Hougaard P, Parving H-H (2005) Progression of microalbuminuria in type 1 diabetes: ten-year prospective observational study. Kidney Int 68:1446-1450

21. Astrup AS, Tarnow L, Rossing P, Pietraszek L, Hansen PR, Parving H-H (2005) Improved prognosis in type 1 diabetic patients with nephropathy: a prospective follow-up study. Kidney Int 68:1250-1257

22. Forsblom CM, Groop P-H, Ekstrand A, Groop L (1992) Predictive value of microalbuminuria in patients with insulindependent diabetes of long duration. BMJ 305:1051-1053

23. Giorgino F, Laviola L, Cavallo PP, Solnica B, Fuller J, Chaturvedi N (2004) Factors associated with progression to macroalbuminuria in microalbuminuric type 1 diabetic patients: the EURODIAB Prospective Complications Study. Diabetologia 47:1020-1028

24. Almdal T, Nørgaard K, Feldt-Rasmussen B, Deckert T (1994) The predictive value of microalbuminuria in IDDM. Diabetes Care $17: 120-125$

25. Warram JH, Scott LJ, Hanna LS et al (2000) Progression of microalbuminuria to proteinuria in type 1 diabetes: nonlinear relationship with hyperglycemia. Diabetes 49:94-100

26. Hallab M, Gallois Y, Chatellier G, Rohmer V, Fressinaud P, Marre M (1993) Comparison of reduction in microalbuminuria by enalapril and hydrochlorthiazide in normotensive patients with insulin dependent diabetes. BMJ 306:175-182

27. Rossing P, Hougaard P, Borch-Johnsen K, Parving H-H (1996) Predictors of mortality in insulin dependent diabetes: 10 year follow-up study. BMJ 313:779-784

28. de Zeeuw D, Remuzzi G, Parving H-H et al (2004) Albuminuria, a therapeutic target for cardiovascular protection in type 2 diabetic patients with nephropathy. Circulation 110:921-927

29. de Zeeuw D, Remuzzi G, Parving H-H et al (2004) Proteinuria, a target for renoprotection in patients with type 2 diabetic nephropathy: lessons from RENAAL. Kidney Int 65:2309-2320

30. Ibsen H, Olsen MH, Wachtell K et al (2005) Reduction in albuminuria translates to reduction in cardiovascular events in hypertensive patients: losartan intervention for endpoint reduction in hypertension study. Hypertension 45:198-202

31. Osterberg L, Blaschke T (2005) Adherence to medication. N Engl J Med 353:487-497 